\title{
Study of the Structure and Parameters of Grid of Hydrogenated Butadiene Nitrile Rubber cross-linked with Polymer Peroxides
}

\author{
S. M. Mammadov ${ }^{1}$, S. A. Rzayeva ${ }^{1}$, A. A. $\operatorname{Garibov}^{1}$, O. N. Akperov ${ }^{2}$, E. O. Akpe rov ${ }^{2}$, J. S. Mammadov ${ }^{1, *}$, \\ S. S. Ahmadova ${ }^{1}$ \\ ${ }^{1}$ Institute of Radiation Problems of ANAS, Baku, AZ 1143, Azerbaijan \\ ${ }^{2}$ Baku State University, Baku, AZ 1143, Azerbaijan
}

\begin{abstract}
Studied the role of poly mer peroxide (1,4-bis-tret butyl peroxy isopropyl benzene) and triazine compounds (2-phenyl-4, 6-bis-trichloro methyl sym triazine) in hydrogenated butadiene nitrile rubber (HBNR) systems HBNR + Poly meric Pero xide, HBNR + Triazine Compounds under heating. By physical and chemical, spectral methods of analysis shown, that the changes in molecular structure of HBNR in the presence of polymer peroxides and triazine compounds. Determined the kinetics of yield and the emergence of cross-linking density of the grid HBNR for each reaserched system depend on time. It is shown that cross linking of the HBNR with pero xide poly mers occurs by a radical type.
\end{abstract}

Keywords Hydrogenated Butadiene Nitrile Rubber, Radiation, Cross-Linking Poly mers, Poly meric Peroxide, Triazine Compounds

\section{Introduction}

In resent has paid increasing attention to cross-linking of high saturated elastomers by using various organic peroxides. The width application as cross linking agents for hydrogenated butadiene nitrile rubber (further HBNR) is derivatives of aliphatic hydrocarbons. For example, di-tret butyl peroxide and di tetrachloride-tret butyl peroxide and etc[1,2].

Early, was shown by the example of study of the influence of aro matic peroxides to cross linking of HBNR, that they have high structure formation properties [3-8]. The presence of small amounts of chain with residual unsaturation in rubber (depends on the structuring groups and the conditions of structure process) allows to regulate the properties of rubber.

Though in the literature[6-8] a row of peroxide-contained carboxy lic acids [3], especially from the point of using tem for vulcanization of saturated rubbers is described, but the products of this row have not yet found technical applications due to the lower temperature of decomposition. While the peroxide compound 1,4-bis-benzene tret butyl peroxy isopropyl (displaced polymer peroxide) has a very

* Corresponding author:

shiraz.mamedov@gmail.com (J. S. Mammadov)

Published online at http://journal.sapub.org/ajps

Copyright (C) 2012 Scientific \& Academic Publishing. All Rights Reserved high half-life and provides a cross-linking in the presence of other cross-linking systems. During cross linking of the HBNR with polymeric peroxides (PP) is usually achieved only a low degree of cross-linking. Obtain ing elastomers is important task, which provides the necessary complex of it's technological and rheological properties. Up to the present time in literature have been no datas about introduction of symmetrical triazine compounds to cross linking HBNR with the polymeric peroxides. More precise datas to this issue are not available, despite the fact that they have the scientific and technical significance to study the influence of structural changes to the grid and the rheological properties of HBNR.

Beside this, to solve the technical tasks of elastomeric materials appointed for oil-processing and engineering industries, 6.0 part by weight of triallyl cyanurate, 3 parts stearic acid, and 5 parts zinc oxide and 50 parts carbon P324 addition is reco mmended[9].

A disadvantage of known structuring systems is the need to conduct vulcanization in two stages, or at high temperatures above $426 \mathrm{~K}$, in which significantly increases the rate of destructive processes, resulting in an increased level of accumulation of residual strains in elastomers at their statistical tests in compression.

High speed and depth of drilling, the high operating pressure to equipment and high temperature in the development and exploitation of oil and gas fields due to the increased requirements to components, they must be a highly durable[10]. 
According to the estimate[11], the annual growth in consumption of elastomeric materials based on special purpose hydrogenated BNR higher than the based on general purpose elastomers and makes 3.8 , and $1.2 \%$.

In the present paper describes studies of the structure of the peroxide elastomers grid from HBNR using the method of sol-gel analysis, as well as by the physical and chemical and spectral methods for research the molecular structure of HBNR in the presence of triazine compounds.

\section{Experimental Part}

As the object of this investigation was used commercially available synthetic HBNR 98\% (Tornak, "Polisar", Canada) which has the following chains in the structure:



and as a cross linking agent used aromatic polymeric peroxide of 1,4-bis (tret butyl peroxy isopropyl benzene, PP).<smiles>CC(C)(C)OOC(C)(C)c1ccc(C(C)(C)OOC(C)(C)C)cc1</smiles>

PP has the following characteristic features: a significant sensitivity to acids, and aliphatic substituent have more beneficial effect than aromatic substituent, has the higher temperature of deco mposition, less sensitive to oxygen.

Degree of cross linking of HBNR is often insufficient achieved only with the use of peroxide. In a jo int application of the peroxides and compounds with polar groups and double bonds, the density of the elastomers grid can be greatly enhanced.

To achieve a high degree of cross-linking was used symmetrical aro matic triazine co mpounds (TAC-2-phenyl-4, 6-bis trichloro methyl symm triazine), whose characteristics given in Table 1. All materials (PP, TAC, HBNR) were represented by "Elastic" (Mingechaur).

Elastomer mixtures based on HBNR containing 8 weight $\mathrm{p}$. of polymeric peroxide, 6 weight p. triazine compounds produced on the mill. To change the physical and mechanical properties of vulcanized rubber, as well as to enhance the process of structuring used 50 parts by weight carbon black (furnace) P-324 and 6 parts by weight epoxy resin as a plasticizer. When choosing a system of carbon black have paid attention main ly to the particle diameter, surface area, oil number and density. Binary and quasibinary system $(\mathrm{HBNR}+\mathrm{PP}, \mathrm{HBNR}+\mathrm{PP}+\mathrm{TAC}, \mathrm{HBNR}+\mathrm{PP}+\mathrm{TAC}+\mathrm{P} 324)$ was heated in electropresse at $423 \mathrm{~K}$ for $120 \mathrm{~min}$ determined the kinetics of Mooney vulcanization on the Montsants rheometer.

Unfilled and filled elastomer mixtures (100 parts by weight of HBNR, 8 parts by weight of PP, 6 parts by weight of TAC, 5.0 parts by weight of zinc oxide, 6 parts by weight of epoxy resin, 50 parts by weight of carbon black P324) after mixing in the rolls during $20 \mathrm{~min}$, then each studied system was heated at $423 \mathrm{~K}$ during $120 \mathrm{~min}$ in elecropresse.

Determined the nature of the PP and triazine compounds action to the change of the characteristic viscosity. The characteristic viscosity $\left[\eta_{\text {char }}\right]$ cross-linking poly mer systems was determined in toluene at $20^{\circ} \mathrm{C}$ by known method[12]. The calculation was performed by the Mark-Houwink equation $[\eta]=\mathrm{KM}^{\alpha}$, at the constant $\mathrm{K}=4,9 \cdot 10^{4}$ and $\alpha=0,64$ for toluene.

The density of the spatial grid and kinetics of vulcanization investigated by changing of the number of chains of the grid $\left(1 / \mathrm{M}_{\mathrm{c}}\right)$ and the number of cross-linking molecules $\left(1 / \mathrm{Mn}_{\tau}\right)$, determined by method of equilibrium swelling samp les in toluene and calcu lated by the equation of Flory-Raineri[13] to the sol-gel analysis for sequential extraction of samples, first with acetone and then with toluene to remove impurities from the rubber. Determination of these parameters is performed according to the sol-gel analys is for sequential extraction of samples with acetone and then with toluene to remove impurities from the rubber.

Changing the molecular structure of cross-linking HBNR determined by IR spectroscopy in the 700-3000 $\mathrm{cm}^{-1}$ range[11]. Vulcanized rubber was dissolved in toluene during $48 \mathrm{~h}$.

Rubber films was obtained by applying the solution onto a substrate for constantly evaporation of the solvent. As substrate used the windows of $\mathrm{KBr}$ in the measurement range of $600-2000 \mathrm{~cm}^{-1}$ and windows of $\mathrm{LiF}$ and $\mathrm{NaCl}$ in the range 2000-3000 $\mathrm{cm}^{-1}$. In avoiding the oxidation the films were dried to constant weight in a vacuum desiccator. The substrate with film was mounted in a holder and placed in the sample compart ment of the spectrophotometer.

Confirmation of a radical mechanism of the chain grid, during cross linking of hydrogenated rubber was maked by research datas of elastomer mixtures at room temperature by RE-1301 spectrometer[15]. Identification of the spectra was performed with the correlation tables[14-17].

Table 1. Characteristics of the used compounds

\begin{tabular}{|c|c|c|c|c|c|c|c|c|c|}
\hline \multirow{2}{*}{ Name } & \multirow{2}{*}{$\begin{array}{c}\text { Mol. } \\
\mathrm{w}-\mathrm{t}\end{array}$} & $\begin{array}{c}\text { Melt. } \\
\text { point, }{ }^{\circ} \mathrm{C}\end{array}$ & $\begin{array}{c}\text { den-ty } \\
\mathrm{g} / \mathrm{cm}^{3}\end{array}$ & solu-ty & phys. state & \multicolumn{3}{|c|}{ Elemental composition } \\
\cline { 6 - 10 } & & & & $\mathrm{C}$ & $\mathrm{H}$ & $\mathrm{N}$ & $\mathrm{pH}$ \\
\hline PP & 338 & $80-82$ & 0.87 & Intoluene & Liquid & 76 & 8.4 & - & 8 \\
\hline TAC & 428 & $88-90$ & 0.93 & Intoluene & $\begin{array}{c}\text { Finely dispers. } \\
\text { powder }\end{array}$ & 64.2 & 6.4 & 28.3 & - \\
\hline
\end{tabular}


Physical, mechanical and exploitation properties of vulcanizates and materials were defined by known $\operatorname{method}[12]$.

\section{Results and Discussion}

All Research has shown that increasing of time of cross-linking (vulcanization) leads to increased molecular mass in both systems (Table 2).

Table 2. Changing the molecular weight of HBNR systems HBNR+PP and HBNR+PP+TAC

\begin{tabular}{|c|c|c|c|c|}
\hline \multirow{2}{*}{$\begin{array}{c}\text { Cross linking system } \\
\text { (weight parts per 100 wt. rubber) }\end{array}$} & \multicolumn{4}{|c|}{ Time, min } \\
\cline { 2 - 5 } & 30 & 60 & 90 & 120 \\
\cline { 2 - 5 } & \multicolumn{4}{|c|}{ The characteristic viscosity $\eta_{\text {char }}$} \\
\hline HBNR + 8PP & 0,2 & 0,4 & 0,5 & 0,6 \\
\hline HBNR+ 8PP+6TAC & 0,4 & 0,5 & 0,7 & 0,9 \\
\hline
\end{tabular}

For a system HBNR+PP at $120 \mathrm{~min}$ the characteristic viscosity is 0.6 , while for the system in the presence of TAC the viscosity higher and its value is 0.9 . Increasing of viscosity in the time range 30-120 min may be related with the formation of spatial structures due to intramolecular cross-linking with poly meric peroxide.

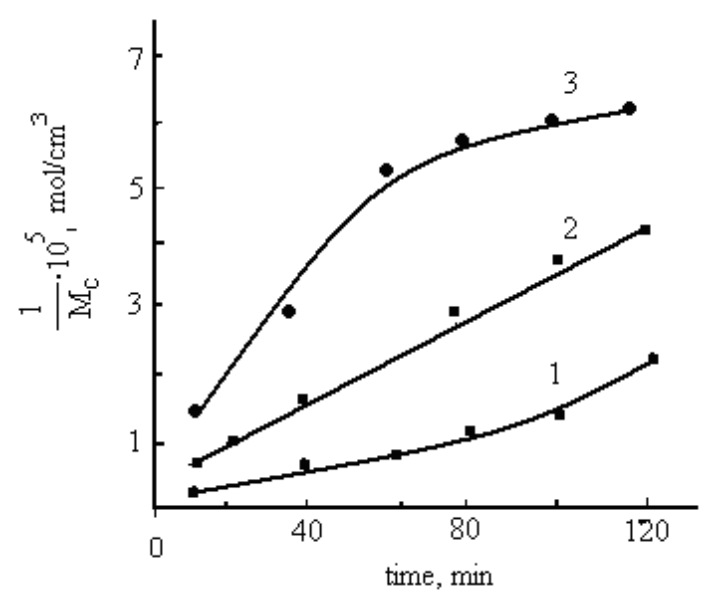

Figure 1. Kinetics of structuring the HBNR(V3850) at 423K; 1- without cross-linking agents; 2 - in the presence of PP; 3 - in the presence of T AC

To evaluate the structuring processes, occurring during the swelling of samples in solution HBNR+PP, HBNR+PP+TAS by sol-gel analysis, the structural parameters of elastomer mesh extracted during $50 \mathrm{~h}$ with cold acetone was determined. The results showed in figure 1 and 2.

It can be seen that the PP significantly influences on the structural parameters of the elastomer. Partial cross linking of HBNR related with a low degree of unsaturation of the rubber. Kinetics of structuring data indicate that in system the rate of cross linking is higher than without PP, the difference is most significant when TAC introduced into the system. Comparative analysis of the cross-linking HBNR shows that the formation yield of cross-links and cross-linked molecules in $30 \mathrm{~min}$ occurs with low rate.
Further, this rate increases with time in both systems. At 120 min the nu mber of chains in the grid system HBNR+PP and $\mathrm{HBNR}+\mathrm{PP}+\mathrm{TAC}$ is 4.2 and $6,3 \cdot 10^{5} \mathrm{~mol} / \mathrm{s} \mathrm{m}^{3}$, and the number of cross-linked molecules is 0.98 and $1,25 \cdot 10^{5}$ $\mathrm{mol} / \mathrm{sm}^{3}$ (Fig. 1, 2).

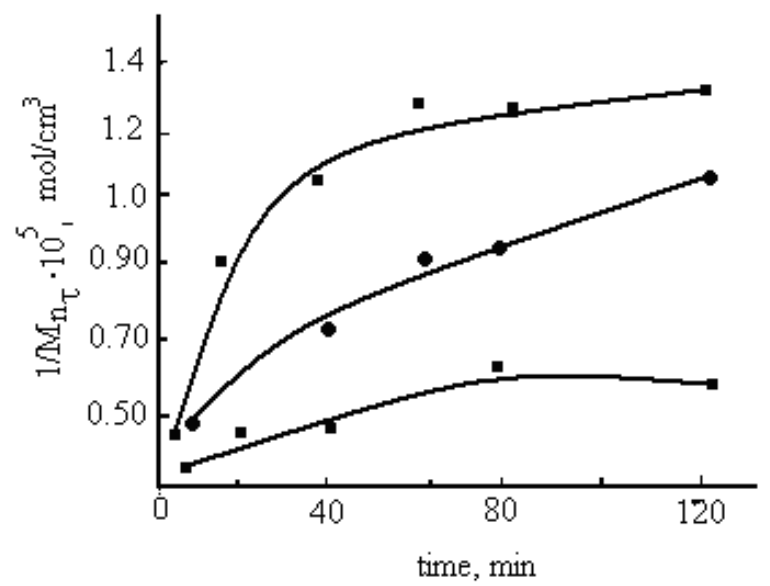

Figure 2. The kinetics of formation of cross-linked molecules, 1- HBNR (V3850) at 423K in systems HBNR; 2- HBNR+ PP; 3-PP+ HBNR + TAC

High sensitivity to cross-linking in the system $\mathrm{HBNR}+\mathrm{PP}+\mathrm{TAC}$ related with the structural features of the low molecular symmetric triazine compound, and the combined action of poly meric pero xide to the density of grid elastomer. Increasing the maximum concentration of chain grid $\left(1 / \mathrm{M}_{\mathrm{c}}\right)$ and cross-linked mo lecules $\left(1 / \mathrm{Mn}_{\tau}\right)$ suggest that cross-lin king in the system(3) leads to the formation of new active centers. Saturated formed peroxy radicals lead to increase cross link and density of elastomers grid. The reaction of low molecular TAC with rubber and the decomposition of PP to the radicals in the chemical reaction promote the formation in rubber macromolecule carbon-carbon structure. The interaction nature of polymeric peroxide to HBNR tried by the change of the IR-spectra (Fig. 3). The system HBNR-PP characterized by the polarity of two polymers, so this process of combining HBNR and polymeric peroxide was determined primarily by polar groups of $\mathrm{C} \equiv \mathrm{N}$ and $\mathrm{C}-\mathrm{O}$, their reactivity under the thermal interactions. On this basis, the main attention was paid to the study of intensity of the stretching vibration of the nitrile group, located in the area of $2235 \mathrm{~cm}^{-1}$ (Fig. 3), and characterized by exceptional stability, both in frequency and form. The intensity of the nitrile band decreases with increasing heating time fro $\mathrm{m} 0$ to $120 \mathrm{~min}$.

Data of IR spectra shows that the polymeric peroxide almost completely have no band corresponding to the absorption of carbonyl group and a doublet at 1805-1765 $\mathrm{cm}-1$, which characterizes the fluctuations of the group CO-OO-CO-. A mong the other most important expositions observed in the IR spectra of samples in the final state, it should be noted decreasing in the intensity of the band 1450 $\mathrm{cm}^{-1}$, which refers to the deformation vibrations of $\mathrm{C}-\mathrm{H}$ bond in $\mathrm{CH}_{2}$ group [14,17], and decreasing the intensity of the band 967 and $1340 \mathrm{~cm}^{-1}$ due out planar and deformation 
vibrations of the $\mathrm{C}-\mathrm{H}$ group, $\mathrm{C}=\mathrm{C}$ trans configuration[17]. By established opinion in literature $[18,19]$, it is assumed that the cross linking of HBNR occurs by joining polymeric peroxide to the double bonds $(-\mathrm{C}=\mathrm{C})$, after heating of HBNR during $120 \mathrm{~min}$. The presence of spectral bands in 1805 and $1765 \mathrm{~cm}^{-1}$ caused by bonds -CO-RO-CO- and $\mathrm{COO}$, which participate in cross-linking, therefore, cross-linking is carried out not only by $2 \%$ unsaturation of the decomposition of polymeric peroxide into radicals, and, apparently, the cross-linking are involved some activated moving ato $\mathrm{ms}$ or reactive centers.

It is known that cross linking of diene rubbers such as by means of peroxide occurs not only as a first-order reaction, but in contrast to the cross linking sulfur compounds, there is a direct proportionality between the flow of cross linking agent (peroxide) and the number of formed cross-linking sites [20]. For this reason, believe that the decomposition of peroxide occurs by hemolytic proceeds with the formation of radical products of cleavage, and cross linking occurs by a radical mechanis $m$ without significant participation of side reactions. These transformations occur usually during cross linking of HBNR, because represented the interest of the detection of radicals formed by the decomposition of polymeric pero xide.

Prior to the research, were studied the EPR spectra of HBNR before and after heating. When heated pure form of HBNR its decompose into radicals, the EPR spectra, which consist of three components, $\mathrm{g}$-factor corresponds to $\mathrm{g}=$ 2,0084 (figure 4a) with line width of $\Delta \mathrm{H}=0.46 \mathrm{mTl}$.



Figure 3. The IR spectra of HBNR-PP after thermal exposure: a- the row sample; b- sustained sample during 2 hours at $423 \mathrm{~K}$

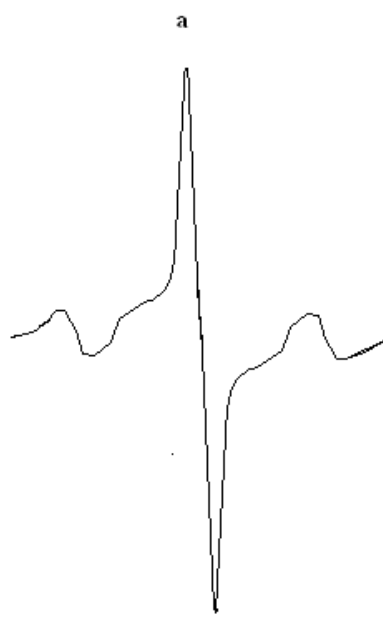

$\triangle \mathrm{H}=1,3 \mathrm{mTl}$



$\Delta \mathrm{H}=1,1 \mathrm{mTl}$



$$
\triangle \mathrm{H}=0,7 \mathrm{mTl}
$$

Figure.4. The EPR spectra after heat ing at $423 \mathrm{~K}$ : a- without addition; b- HBNR+PP; $c-H B N R+P P+T A C$ 
ERP spectra observed for a mixture of HBNR - PP is typical for systems with a poly meric peroxide, has a narrow singlet line $\Delta \mathrm{H}=1.1 \mathrm{mTl}$ unchanged g-factor (figure $4 \mathrm{~b}$ ). Heating of systems containing PP + TAC leads to a different number of researched paramagnetic centers and a drastic reduction of the spectrum (figure $4 \mathrm{c}$ ), in which the width of the band was $\Delta \mathrm{H}=0.7 \mathrm{mTl}$. Thus, in the presence of PP concentration of radicals decreased 1.5 times in comparison with the system HBNR+ PP (figure 4b). By studying the way or the other behavior of polymeric peroxide in elastic environment, we can make a finished conclusion of the microstructure of the molecular chains of elastomer. Based of experimental and literature data[21,22], we must assume that the emergence of a radical with no excess of fine structure due to the fact that at the beginning of peroxide cross linking polymer decomposes mainly into two radical $\mathrm{R}-\mathrm{O}-\mathrm{O}-\mathrm{R} \rightarrow 2 \mathrm{R}-\mathrm{O}^{\circ}$. These radicals are stabilized again in the presence of hydrocarbon polymers. And they are dehydrogenated polymer chain, and carry it in a radical state:

$$
-\stackrel{\mathrm{C}}{\mathrm{C}}+\mathrm{RO}^{*}-\mathrm{C}_{\mathrm{l}}^{*}+\mathrm{ROH}
$$

Thus resulting hydrocarbon radical may react with the same radical, creating cross-links.

$$
-\underset{l}{\mathrm{C}}+\underset{\mathrm{l}}{\mathrm{C}}-\stackrel{\mathrm{I}}{\mathrm{C}}-\underset{\mathrm{l}}{\mathrm{C}}-
$$

Founded on the obtained experimental data, we can conclude that the lateral nitrile group in the main chain saturated hydrocarbon units, as well as unsaturated butadiene units (within 2\%) to allow cross linking of hydrogenated natural rubber in the presence of polymeric peroxides (1,4-bis-tert butyl peroxy isopropyl benzene .) It is easily decomposed at $423 \mathrm{~K}$ with satisfacted yields in the macromolecule cross-links and cross-linked molecule within the time 30-120 $\mathrm{min}$. To achieve a higher degree of cross linking should enter for the enhanced triazine compounds (2-phenyl-4,6-b is (trichlo ro methyl) - sym triazine). Ho wever, the role of the TAC, causing the observed changes of the properties HBNR, subject to further study.
In Table 3 presents the results of physical-mechanicaltests of mixtures. The results showed that the process of structuring HBNR with poly meric peroxide without carbon black is slow and the degree of cross linking is low (Fig. 5, Table 3). In the presence of TAC ( 8 weight p. per 100 parts by weight of rubber) and carbon black and the rate of cross linking in the macromolecule at $423 \mathrm{~K}$ practically does not decrease compared without carbon black. It's clearly seen fro $m$ the kinetic curves changing of $v$ iscosity of the mixture at $423 \mathrm{~K}$ (Fig. 5 curve 2 ).



Figure 5. The kinetics of the change of viscosity in mixtures based on HBNR with carbon and without in the process of heating at $423 \mathrm{~K}$ in the rheometer Montsant. 1. HBNR+ PP+T AC; 2. HBNR+PP+T AC+P324

The acceleration of cross-linking, possibly related with dissociation of the peroxide and triazine groups around the carbon black particles, as well as mo re polarized bond (C-C) in allyl group, as a molecule of PP and TAC is very polar.

If we consider a filled polymer as a colloidal system in which the poly mer is the dispersed phase, apparently during cross lin king HBNR with poly meric peroxide carbon black acts as a dispersed phase[23]. The foregoing hypothesis can be extended to a study in this paper in the system HBNR+ $\mathrm{TAC}+\mathrm{PP}+\mathrm{P} 324$

Therefore, the introduction of metal oxide and an epoxy resin (ED-40) significantly affects the cross-linking at heat treatment (Table 4).

Table 3. Changing the molecular weight of HBNR systems HBNR+PP and HBNR+PP+TAC

\begin{tabular}{|c|c|c|c|c|c|}
\hline Composition & $\begin{array}{c}\text { Duration of } \\
\text { structuring, } \\
\tau, \mathrm{min}\end{array}$ & $\begin{array}{c}\text { The number of } \\
\text { cross-linking, } \\
\mathrm{Nc} \cdot 10^{-19}, \mathrm{~cm}^{3}\end{array}$ & $\begin{array}{c}\text { Resistance } \\
\text { at break, } \\
\mathrm{f}, \mathrm{MPa}\end{array}$ & $\begin{array}{c}\text { Elongat ion, } \\
\varepsilon, \%\end{array}$ & $\begin{array}{c}\text { Hardness by } \\
\mathrm{HM}, \mathrm{mm}\end{array}$ \\
\hline \multirow{3}{*}{ HBNR+PP+TAC } & 20 & 1,9 & 8 & 820 & 20 \\
& 60 & 4,1 & 10 & 790 & 35 \\
& 120 & 5,3 & 12 & 710 & 40 \\
\hline HBNR+PP+TAC +P324 & 20 & 3,8 & 12 & 770 & 30 \\
& 60 & 6,4 & 11,0 & 600 & 40 \\
\end{tabular}


Table 4. The yield concentration of effective cross-linking ( $\left.{ }^{\prime}{ }_{c}\right)$ of sulfuric and peroxide filled vulcanizates HBNR

\begin{tabular}{|c|c|c|c|}
\hline Vulcanızing system & $\begin{array}{c}\text { Chemical } \\
\text { Bond }\end{array}$ & $\begin{array}{c}\text { Mooney } \\
\text { viscosity } \\
\text { c.u. }\end{array}$ & $\begin{array}{c}\text { Amount } \\
\text { of cross } \\
\text { linkmg, } \\
\left(\mathrm{n}^{\prime} \cdot 10^{-19} \mathrm{~cm}^{3}\right)\end{array}$ \\
\hline $\begin{array}{c}\text { HBNR (satur. 95\%) } \\
+\mathrm{S}+\text { kaptax+ZnO [24] }\end{array}$ & C-S-C & 55 & 5.4 \\
\hline $\begin{array}{c}\text { HBNR (satur.97\%)+ } \\
\text { DKP*+PPR**+ZnO[25] }\end{array}$ & C-C & 61 & 6.2 \\
\hline $\begin{array}{c}\text { HBNR (satur.98\%)+ } \\
\text { PP+TAC+ER+ZnO[9] }\end{array}$ & C-C & 72 & 8.9 \\
\hline
\end{tabular}

DKP* - dikumilperoxide

PPR ** -phenol phormaldehyde resın

In determining of the physical and mechanical properties of filled elastomers based on HBNR found that the TAC and the epoxy resin duringcross linking are reactionable. Sulfuric and dikumilo peroxide cross linking vulcanizates (1.2) yield polymeric peroxides in composition (3), in the strength and resistance to thermal aging, and the action of solvents (Table $5)$.

Table 5. Comparative properties of filled HBNR vulcanisates

\begin{tabular}{|c|c|c|c|}
\hline \multirow{2}{*}{ Parameters } & \multicolumn{3}{|c|}{ Vulcanization } \\
\cline { 2 - 4 } & HBNR 95\% & HBNR 97\% & HBNR 98\% \\
\cline { 2 - 4 } & $\begin{array}{c}1 \\
\text { C-S-C }\end{array}$ & $\begin{array}{c}2 \\
\text { C-C }\end{array}$ & $\begin{array}{c}3 \\
\text { C-C }\end{array}$ \\
\hline $\begin{array}{c}\text { Resistance } \\
\text { at break, f, MPa }\end{array}$ & 18 & 15 & 21 \\
\hline Elongation, \% & 550 & 570 & 480 \\
\hline $\begin{array}{c}\text { Hardness } \\
\text { (by TM-2), c.u. }\end{array}$ & 57 & 55 & 64 \\
\hline $\begin{array}{c}\text { Compression set } \\
\text { (20\%, 423K, 72h) }\end{array}$ & 70 & 62 & 5 \\
\hline $\begin{array}{c}\text { Coefficient of } \\
\text { thermal aging, } \\
423 \mathrm{~K}, 150 \mathrm{~h}\end{array}$ & 0,61 & 0,53 & 0,85 \\
\hline $\begin{array}{c}\text { Change of mass } \\
\text { due swelling in a } \\
\text { mix } \\
\text { of }\end{array}$ \\
$\begin{array}{c}\text { gasoline-benzene } \\
\text { (3:1) (353K, 24h), } \\
\text { \% (weight) }\end{array}$ & 54 & 48 & 35 \\
\hline
\end{tabular}

To determine the effect of temperature and exploitation conditions to the performance of elas tomeric materials (EM) was carried out comparative tests to the vulcanizate HBNR at $423 \mathrm{~K}$ in hostile environment (Table 6), in which working the seals, swivels, pumps (U8-6MZA) and other units of the oil industry. These data indicate that the experimental elastomers containing in their structure TAC and a metal oxide, have the less degree of swelling and accumulation of residual compressive strain. Tensile strength after contact with the medium to 1.2 was lower than to 3 .

Thus, the analysis of the results of studies suggests that elastomeric materials based on HBNR and obtained in the presence of cross linking poly mer pero xide agent (PP), TAS and epoxy compounds, is superior of sulfuric and dikumilo peroxide elastomers in resistance to thermal aging and dynamic endurance during repeated stretching in corrosive environment. All studied compounds were recommended for use in the formulations of sealing manufacture of EM parts of drilling equip ment.

The use of these research results, the creation of stable elastomeric materials of drilling technology reduces the halting of pumps and swivels in the drilling process and ensures continuous operation of the plant.

This work was supported by the American Foundation of Fundamental Research (Grant N AZC-0905).

Table 6. Comparative datas of the filled EM based of different sat urated HBNR after use in sea water (I), oil-bearing (II) and mud solutions (III). Test mode $423 \mathrm{~K}, 72 \mathrm{~h}$

\begin{tabular}{|c|c|c|c|}
\hline \multirow{3}{*}{$\begin{array}{l}\text { Parameters } \\
\text { (test mode } \\
423 \mathrm{~K}, 72 \mathrm{~h} \text { ) }\end{array}$} & \multicolumn{3}{|c|}{ Vulcanization } \\
\hline & HBNR 95\% & HBNR 97\% & $\begin{array}{c}\text { HBNR } \\
98 \% \\
\end{array}$ \\
\hline & $\begin{array}{c}1 \\
\text { C-S-C } \\
\end{array}$ & $\begin{array}{c}2 \\
\mathrm{C}-\mathrm{C} \\
\end{array}$ & $\begin{array}{c}3 \\
\mathrm{C}-\mathrm{C} \\
\end{array}$ \\
\hline \multicolumn{4}{|l|}{$\begin{array}{c}\text { Strenght of } \\
\text { rupture }\left(f_{p}\right), \mathrm{MPa}\end{array}$} \\
\hline I & 10 & 9 & 14 \\
\hline II & 13 & 11 & 15 \\
\hline III & 15 & 13 & 16 \\
\hline \multicolumn{4}{|l|}{$\begin{array}{c}\text { Coefficient of } \\
\text { thermal aging, }(\mathrm{I}, \mathrm{II})\end{array}$} \\
\hline By heat. $\left(f_{p}\right)$, & 0,52 & 0,45 & 0,71 \\
\hline By cond.un. $\left(\varepsilon_{\mathrm{p}}\right)$ & 0,7 & 0,6 & 0,82 \\
\hline \multicolumn{4}{|l|}{$\begin{array}{l}\text { Change in mass due } \\
\text { swelling, \% (weight.) }\end{array}$} \\
\hline I & 235 & 198 & 125 \\
\hline II & 98 & 104 & 88 \\
\hline III & 71 & 83 & 59 \\
\hline
\end{tabular}

\section{Conclusions}

In this paper we studied the effect of polymeric peroxide to the process of cross linking of HBNR (Tornak V 3850, Canada). To achieve a higher degree of cross linking symmetrical triazine compounds actuator was injected into the elastomer. By the method of capillary viscometer specified that for the systems $(\mathrm{HBNR}+\mathrm{PP})(1), \mathrm{HBNR}+\mathrm{PP}$ +TAC (2) during 30 minutes the time of the characteristic vis cosity is 0.2 and 0.4 . W ith increasing time $(120 \mathrm{~min})$ of the structuring, the molecular weight increases as well. In the time more than $120 \mathrm{~min}$ characteristic viscosity decreases. The decrease of mo lecular weight of rubber occurs as a result of destruction of the polymer chain. Increasing of the viscosity in the range of 30-120 minutes related with formation of spatial structures due to intermolecular cross linking reactions. The study of the structural parameters (cross linking with polymeric peroxide and with symmetric triazine compounds by the sol-gel analys is) revealed that the yield number of mesh of butadiene chain in the time range $30-120 \mathrm{~min}$ for systems 1 and 2 is 4.2 and $6,3 \cdot 10^{5} \mathrm{~mol} / \mathrm{sm}^{3}$. A number of cross linking is 0.98 and $1.25 \cdot 10^{5} \mathrm{~mol} / \mathrm{s} \mathrm{m}^{3}$. 
The study of IR spectra of HBNR cross linking with polymeric peroxides (1,4-bis-benzene tret butyl peroxy isopropyl) shows that in the IR spectra of the polymeric peroxide almost completely absent. The band corresponding to the absorption of carbonyl group, and there is doublet at $1805-1765 \mathrm{~cm}-1$, which characterizes the fluctuations of the group -CO-RO-CO-. By adding polymeric peroxide to double bonds and the appearance after heating $(423 \mathrm{Kx} 120$ ') spectrum band in 1805 and $1765 \mathrm{~cm}^{-1}$ are related by bonds-CO-RO-CO- and $\mathrm{COO}$, which participate in cross linking. Consequently, the cross linking is carried out not only by $2 \%$ unsaturation, but the structure HBNR has a decisive influence on the rate of cross linking. Probably in the cross-lin king are involved more activated moving atoms or reactive centers.

Analysis of ESR spectra revealed that the reaction with the polymeric peroxide and HBNR, the polymeric peroxide decomposes into radicals without the excess of the fine structure. These radicals are stabilized again in the presence of carbon polymers, resulting hydrocarbon radical may react with the same radical, creating cross-links.

To determine the effect of temperature and exploitation operating conditions to the performance of the EM were carried out laboratory tests at $423 \mathrm{~K}$ in corrosive environment of materials based on HBNR. It is shown that in the investigated EM, made with indicated composition, the degree of diffusion, the accumulation of residual strain in compression and physico-mechanical properties under dynamic loads stay the same.

\section{REFERENCES}

[1] Mamedov S. M., Yadreev F. I., Rivin E. M. Butedien-nitrilniy e kauchuk i rezini na ikh osnove. Baku: Elm, 1991. p.157.

[2] Lisova G. A., Dontsov A. A. Gidrirovanniye butadiene-nitrilniye kau chuki, svoystva, retsepturostroeniye, primeneniye. Tematicheskiy obzor. M: TSNIITEneftekhim, 1991. 55p.

[3] Waqner. D. // Kautsch., Gummi. Kunstst. 1983. v. 36. №6.p. 515 .

[4] Peterson. R. Eur. Rubber // J. 1985/ V/ 165. №6. p. 115.
[5] Mamedov S.M. Jurn. prikl. khimiyi. 2005. T. 78. vip. 9. p. 1556.

[6] Smith A. P., Aubar T. L., Herd C. R. // Rubb. Chem. Technol. 2004. v.75. № 4. p. 691.

[7] Justin B. // Eur. Rubber. J. 2004 v.186. № 9. p. 10.

[8] Furakawa J., Iseda T. Rubb. World. J. 1993 v.167. № 4. p. 36.

[9] Pat. I2011 0094. Azerb MKI S 08 K 3/10 F8/04

[10] Tornac Rubber. Molecular structure. Polysar and polysar are trademarks of nova Corporation of Alberta. MS-1, 09-88. Printed in Canada.

[11] European Rubber Journal. 1999 Vo. 171, No 3, p.20

[12] Kuznetsov E.V., Divgun S.M., Budarina S.M., Budarina L.A. I dr. Praktikum po khimii I fiziki polimerov. M.: Khimiya, 1977. p. 380 .

[13] Flori p., Rehuian İ. İ. // Chem. Phys. 1948, №11. P. 512.

[14] Nelson K. V. Kolebatelniye spektri i molekularniye protsessi v kauchukax. Sb. tr. VNIISK. L.: Khimiya. 1970. p. 150.

[15] Ingram D. Elektronniy paramagnitniy rezonans v svobodnikh organicheskikh radikalakh. Per s angl. M.: Izd-vo inostr. Lit. 1987. C.

[16] Bakhishev N.G Spektroskopiya mejmolekulyarnix vzaimodey stviy. L.: Nauka, 1972. p347

[17] Dekhant I., Dants R., Kimmer V, Shmolke R. Infrakrasnaya spektroskopiy a polimerov. M.: Khimiya. 1976.

[18] Hashimoto K. // Rubb. Chem. Tchnol. 1986. v.59. № 1. p. 161.

[19] Thower J., Merwede g. // Kautsch., Gummi. Kunstst. 2003 Bd 36. №4. p. 269.

[20] Weinstein A. // Rubb. Chem. Tchnol. 1984. v.57. № 1. p. 203.

[21] Wanq X. // Eur. Rubber. J. 1989 v.171. № 3. p. 20.

[22] Hofman V. Vulkanizatsiya i vulkanizuyushiye agenti. M. Khimiya, 1968. p.

[23] Reactivity, Mechanism and Structure in Polymer Chemistry. Edited by A.D.Jenkins \&A.Ledwith, M: Izd. "Mir",.1977 p 645 .

[24] Mirza J. e.a.// Kauts. Gummi Kunst. 1996. -Bd 39. No 7.p 615-620

[25] Hofman W. J. Kautschuk u.Gummi. Kunst. 1994. 13d 37. No9. p 753 